\section{Food Security in Africa}

\section{2-5 December 2007, Stellenbosch, South Africa}

Stellenbosch University will host CHEMRAWN XII, an international conference on the role of chemistry in sustainable agriculture and human well-being in Africa. The conference, which will take place 2-5 December 2007 in Stellenbosch, South Africa, is part of the CHEMRAWN series of conferences. CHEMRAWN, or Chemical Research Applied to World Needs, is a Standing Committee of IUPAC.

The conference has already attracted recognized scientists from various African countries and elsewhere as speakers and workshop presenters. The keynote address will be delivered by Pedro Sanchez, a former recipient of the World Food Prize and currently the director of Tropical Agriculture at the Earth Institute, Columbia University.

The academic program will

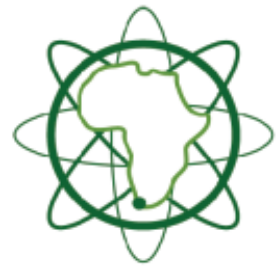
focus on improving the quality of life of the peoples of Africa through the provision of adequate food, with specific attention to the role of chemistry. The goals of the program are as follows:

- come to a better understanding of sustainable agriculture in Africa in a globalized market

- develop a systems approach to optimizing food provision in Africa

- $\quad$ utilize high technology in ensuring food security in Africa
- highlight chemistry as a core science for food security in Africa

- take advantage of agricultural produce from Africa as a source of high value and niche products

- $\quad$ promote science-based capacity development at universities as a prerequisite for food security in Africa

The conference organizers endeavor to attract top scientists, research students, industrialists, and policymakers involved in the food chain in Africa to the conference and to ensure that the findings of the conference are well communicated and acted upon.

Pieter Steyn, chairperson of the conference organizing committee, says: "The holding of CHEMRAWN $\mathrm{XII}$ is most timely as evidenced by recent events. The provision of safe and adequate food is very high on the political and economic agenda in Africa and the proposed

STELLENBOSCH XOQ7 coincides with Africa's Science and scientific program coincides with Africa's
Technology Consolidated Plan of Action."

Interested persons are invited to visit the conference website, or to contact the secretary of the conference organizing committee, Christoff Pauw <cpauw@sun.ac.za> for more information.

See Mark Your Calendar on page 40 for contact information.

iii. www.chemrawn.co.za

\section{Space Research}

\section{3-20 July 2008, Montreal, Canada}

The 37th COSPAR Scientific Assembly and 50th Anniversary Celebration will be held from 13-20 July 2008 in Montréal, Quebec, Canada. COSPAR is the Committee on Space Research of the ICSU, now the International Council for Science. COSPAR's objectives are to promote on an international level scientific research in space, with emphasis on the exchange of results, information and opinions, and to provide a forum, open to all scientists, for the discussion of problems that may affect scientific space research.

The conference will feature approximately 85 meet- ings covering a wide range of topics, including Earth's Surface, Meteorology, and Climate; Upper Atmospheres of the Earth and Planets; Materials Sciences in Space; Fundamental Physics in Space; Satellite Dynamics; Potentially Environmentally Detrimental Activities in Space; and Space Weather, among many others.

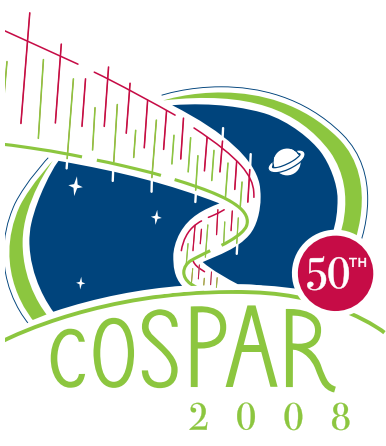

Papers from the conference will be published in Advances in Space Research.

2ing www.cospar2008.org or www.cospar-assembly.org 